\title{
Photographic Representation of Socio-economic Development on Rural Communities in Ghana
}

\author{
Dr. Joseph Essuman \\ Department of Graphic Design, University of Education, P. O. Box 25, Winneba, Ghana
}

\begin{abstract}
It has come to notice that developments that take place in rural communities bring about a lot of challenges both positive and negative. However, people who try to manage these challenges use "text type" in books and through other communication media (publications), but the effect has scarcely been effective because, most of the people living in rural communities are illiterates. The purpose of this study was to use pictorial illustrations to create awareness on how socioeconomic development affects rural communities (Cape Three Points) and the extent to which its effect can be seen on human life within the local communities (fishermen, farmers, and fish mongers) in terms of their livelihood, attitudes, education and on the general environment. Interviews were mainly used to ascertain facts on how the situation was before the new developments started. Workshops were also organized for focus groups, through which the effect of pictorial illustrations on the people were ascertained. Again, how they should prepare for the foreseen changes that will emanate from any form of rural development was also discussed. At the end of the study, it came to light that many of our rural areas face significant challenges. These challenges as a matter of fact affect their cultural practices and the socio-economic development of the people in such rural communities and the country as a whole. It is believed that these challenges and many other related concerns that have emanated from this study would be critically recognized and managed if not solved by the powers that be. Results from this study will form a basis for further discussion of socio-economic effects of rural development on rural communities and any other related effects caused by any physical change on rural environment.
\end{abstract}

Keywords: development, rural community, socio-economic, illustration

\section{Introduction}

For most human history, people used subsistence technological tools, processes, and knowledge that a society requires to meet its basic needs for survival. In view of this, the need of adequate food supply was satisfied through fishing, farming, hunting, and foraging for fruits or vegetables from the immediate environment and beyond. According to Schaefer and Lamm (1995), rural development as a matter of concern is a means of promoting economic, ecological, socio-cultural and political-institutional aspects in equal measure. These approaches they say, aim to achieve sustainable growth that benefits the whole of society. Schaefer and Lamm (1995) are of the view that rural development also helps to improve food security and promote health in such communities. It further helps to create income and employment opportunities and thus the necessity for 
successful economic development. However, with the current level of industrialization, industrial societies depend much more on the physical environment to transform it to suit the recent global changes. The transformation of the physical environment (which is termed as rural development) one way or the other, affects human life in the rural communities.

It is common knowledge that people living in most coastal rural areas are fishermen, fish mongers and peasant farmers. It is also palpable to say that, since the main occupation of the rural and coastal folks are fishing, farming and women a fish mongers, the westernized form of education is very low.

The main objective of this article is to use pictorial illustrations to create awareness on how socio-economic development can affect rural communities most especially at Cape Three Points in the Ahanta West District in the Western part of Ghana. It is hoped that, if the above objective is achieved, it will enable the people within the rural community to comprehend the link between their immediate personal social settings and their "remote" impersonal social world that surrounds them, so as to shape them appropriately. It is pertinent to discuss the key words used in this article in order to promote an understanding of them in the light of their usage here.

\section{Development}

The term development in international parlance encompasses the need and the means by which to provide better lives for people in poor countries. It includes not only economic growth, although that is crucial, but also human development-providing for health, nutrition, education, and a clean environment (Escobar, 1995). Development, therefore, becomes the act of improving quality of life and making sure everyone has the preference in what that life looks like. People living in rural communities have imbued in them some social and economic adoptions that must be respected. However, in a more economic sense, The Business Dictionary (2014) is of the view that, development is the process of economic and social transformation that is based on complex cultural and environmental factors and their interactions. This means that a major societal shift in one dimension, for example from a rural or agriculture-based society to an urban or industrial-based society (what is sometimes called the shift from "traditional” to "modern" characteristics), would also have radical implications in another dimension, such as societal structural changes in the respective positions of classes and groups within the relations of production (Escobar, 1995). This suggests that development involves changes to socio-economic structures-including land and property ownership, production process, cultural and institutional structure, laws and technology. It is hoped that if the socio-economic structures are properly organized, it goes a long way to affect the economy positively. Here, both the elders of the rural communities and developers come to an agreeable course to chart so that their respective cultures are not infringed upon. It is by this that Hickey and Mohan (2014) state that, by revealing the situatedness of interpretations of economy and poverty, post-modern approaches look for alternative value systems so that the poor are not stigmatized and their spiritual and cultural "assets" are recognized. By this approach, the researcher opines that any socio-economic development on any rural community that is structured on compromise, will bring economic benefit to both parties and for a healthy socio-economic transformation.

\section{Rural Community}

According to the Bracken (2006) rural community is characterized by having low population densities, 
limited resource base, relative isolation and cultural or ethnic homogeneity. It further states that a rural community is one that is not developed and consists mainly of farms or largely unsettled land. Ordinarily, it could be deduced from the above definition that, a rural area is a remote area where development is low. It could also be one that is typically conservative, with a local economy centred on farming and fishing. Hence, people living in such areas customarily have their own societal settings which they so much uphold. To buttress this, Ritchey (2006) echoes it by saying that, the rural community is made up of low population density but adds that the people have a local-based independence character, a connection to nature and shared values or responsibility as aspect of rurality.

\section{Rural Development}

According to Moseley (2003) rural development generally refers to the process of improving the quality of life and economic well-being of people living in relatively isolated and sparsely populated areas. In view of this, rural development may be defined as overall development of rural areas to improve the quality of life of rural people and in general, it could be used to denote the actions and initiatives taken to improve the standards of people living in non-urban neighbourhoods, countryside and remote villages. This development process becomes an integrated process, which includes social, economic, political and spiritual development of the poorer sections of the society. It could therefore be said that, rural development one way or the other, affects the economic and social fabric of any society. Schaefer and Lamm, 1995 say, a key element in the sociological imagination is the ability to view and understand one's own society as an outsider would, be rather than from the limited perspective of personal experiences and cultural biases. Hence, the large scale oil production at Cape Three Points (CTP) in the Western Region, should correlate with the community's development.

Feasibly, an outsider unfamiliar with the CTP community may not understand why the exploration and production of oil should not be a reality, because his or her mind is only "tuned" to how the production will bring economic benefit to the state and also international recognition, without thinking deeply about the repercussions the sudden environmental change will bring onto the community at large. Moon (2014) states that, The United Nations Millennium Declaration and the associated Millennium Development Goals (MDGs) mark the start of a new global partnership for development. It is again of the view that, as the majority of the world's poor live in rural regions, rural development makes a tangible contribution to structural poverty reduction. The declaration advances that, rural development aims at fostering the partner countries' productive potential in accordance with the principle of environmental sustainability and develops national and global structures by delivering policy advice in the fields of agriculture, food security, agricultural trade, coastal zone and land management policy. The aim of the MDGs is to enable people in rural regions to devise their own sustainable methods and solutions.

The fillet of contention is that, how people who live in rural communities (illiterates) could devise their own sustainable methods and solutions to a road map that has been set by other people without involving the people concerned. The researcher believe that the involvement of the people within the rural communities would rather educate them to accept the challenges ahead and try and find proper solutions before these new ideas are effected. Some of these developments affect cultural practices. It also trickles down to affect the people whose cultural practices have been changed, because culture is an integral part of every society (buzzle.com, 2011). Culture is a 
learned pattern of behaviour and ways in which a person lives his or her life and essential for the existence of a society, because it binds people together but in an explicit sense of the term, culture constitutes the music, food, arts and literature of a society (buzzle.com, 2011). Culture is a learned and transmitted social behaviour of a society. The beating of gongong and now the use of mounted speakers for information dissemination are good examples.

In view of the above assertions, it could be said that, there should be effective pictorial illustrative education for people who live in any rural community where rural development is to take place or has already taken place so that they can adjust to any changes that may affect them in the near future. Also both literates and illiterates in rural communities will acquire certain explicable knowledge that could be used to develop their own full potentials. To buttress this, Essuman (2002) cites Ross (1969) who said any education worthy of the name can do no less than foster those inventive powers of man that ensures his mastery over the material given him. It is also believed that education in itself advocates for self-reliance and for that matter after acquiring knowledge about an experience, there is the need to apply such knowledge to life. Hence, there is the need for this education to be given to people within the CTP communities where developments are to take place, so that they will know what awaits them in future for their readiness and adjustment to the changes effectively.

\section{Socio-economic Development}

According to Hall (2014) socio-economics is defined as a multidisciplinary approach to studying economic phenomena and the social implications and effects that result from those phenomena. Many socio-economic studies according to Hall (2014) examine the social effect of economic events, such as recessions, factory closings, unemployment or international trade agreements. He reiterates that the social consequences of such explicitly economic events can be limited to a single community or can be regional, national or even international in scope. Taking the study under review for example, the social effects of drilling oil at Cape Three Points in the Western Region will not only affect the people in that area but have a wide economic and social consequence on other surrounding areas and in this case, Sekondi/Takoradi will be no exception.

Any form of rural development has its positive and negative implications. Undoubtedly, the negatives usually out-weigh the positives in each case. Tella et al. (2001) indicate that, unemployment for example is a major economic and social issue. It causes serious economic decline as the standard of living in countries reduces. Unemployment causes social inequality since members of the public suffer from a decreased earning capacity and minimal economic activity. In view of this, there is the need for proper pictorial illustrative education to be given to the communities where development is to take place or has taken place so that socio-economic issues such as education, cultural and religious discrimination and unemployment are agreeably dealt with so as to bring satisfaction to involving parties.

\section{Illustration}

An illustration is a representation or a depiction made by an artist, it could be in the form of drawing, sketching, painting and photograph of images that are found within the artist's surroundings. They are used to explain, prove or make text types clear and easy to understand. It enhances and gives vitality and intensity to written texts and further gives clearer meaning to any form of written document. To buttress this, Nesterov (2014) 
advices that, use illustrations if you want to convey an idea which is difficult to express or it would take a lot of time to explain and describe what you mean. This suggests that illustration best draws attention of the viewer to information than text type. Text types undeniably, are comfortably read and understood by the literates in the society. Unfortunately, it is not so with illiterates. As stated earlier in the study, most rural areas are occupied by semi-illiterates or total illiterates hence, in order to disseminate any important information, it is appropriate that it is done exclusively with pictorial illustrations or illustration with very little text type. Here both literates and illiterates would have equal chance of reading meaning to whatever information that is being propelled across. By this, persons in the community will understand and make useful contributions towards any societal change that may happen to the community.

Illustrations are widely used for teaching people of all ages in foreign languages, for presentation of complicated scientific and engineering concepts. Illustrations are needed for all kinds of instructional literature for better understanding of the material (Nesterov, 2014). It is no wonder then, that children's books are usually filled with pictorial illustrations, because the use of those illustrations becomes a direct means of communicating to them rather than graphically and ornamentally designed written text material. This is buttressed by Spaulding (2014) as he states:

...obviously, illustrations are used to simulate interest and to extend and clarify the meaning of the accompanying printed material. Oddly enough, although many studies have concerned themselves with the effectiveness of the printed word in creating interest and communicating ideas, very few studies have considered the varying effectiveness of pictorial illustration as a communication medium. (Spaulding, 2014, p. 35)

After all it is also an undeniable fact that, the ability to understand and remember the content of any manual document is usually enhanced by an accompanied illustration. It, therefore, becomes necessary to use pictorial illustration to educate the people of CTP in the Western Region of Ghana on the effect of the oil production on them, so that effective remedial measures are put in place; and help solve any socio-economic issues that may affect the society.

\section{Methodology}

To achieve the objective set earlier, the qualitative and descriptive research methods were used. The qualitative method was used because the study required the researcher to visit the members of the communities under review. This was done to collect data on the prevailing situation on the ground for the study through organization of workshop for a group of people within the CTP community and other related communities. The descriptive research method was also used to specifically describe the real situation in the communities.

Of the 40 respondents who were randomly selected for the study, only 4 of them were those who ended their education in Forms One and Two in the Junior Secondary School level. Besides that, all the 4 were young men. The rest of the 36 respondents were those who could not get to Primary Six and even below. Interestingly, out of the 36 respondents which form $90 \%$ of the population, 2 of them, representing $5 \%$ were young women. In view of this, the uproar about rural development and its socio-economic effect in "texts type" information would not be effectively felt by the people within the rural community if appropriate pictorial education is not given. The use of text type information in the education of rural development has been a history of failure, resulting more often in strengthening the position of traditional elites than integrating the poorer elements in the rural 
communities into natural development process. There is therefore the need to educate people within local communities where rural developments are to begin or has begun, on how such changes can affect them using pictorial illustrations.

First of all, the researcher organized a workshop and presented text materials from the newspapers indicating how the oil production is to be explored in the CTP community. Changes that may affect the community were also shown to the selected group for the study. It was realized that, the text type did not have any impact on the people because most of them could not read and understand the resultant effect of how the development could affect them. Again, the few educated ones amongst them could not read with meaning and for that matter could not understand what had been read. Pictorial illustrations of Aboadze in the Shama district of the Western Region, a typical example of a rural community that had undergone similar physical environmental changes were shown to participants. This was done for them to have a fore knowledge on how such changes could affect their daily activities. Again, pictorial illustrations of how Volta River Authority (VRA) workers' township at Aboadze had been mechanically constructed were also shown to them. These comprised of their bungalows, road networks, recreational facilities, school facilities for children and a newly built hospital facility for the community. To end the workshop for the participants, some parts of the Aboadze township itself were also shown to them. This was done to show them how distraughtly and neglectedly the CTP community could turn to be after any such physical environmental development occurs.

\section{Findings and Discussions}

After going through the various illustrations, individuals in the group were then made to share their views in turns on how such changes could affect them in the near future. The workshop produced credible responses that assisted the researcher to conclude and made effective recommendations on the study. Participants were enthused about the graphical and vivid nature the situation at Aboadze has been presented in pictures. The deserted Aboadze Township, Figure 1a and Figure 1b suggested to them how their communities would be if steps are not taken to put effective measures after the so called development has taken place. Figure 2 gave a clear indication of the poor road network in the Aboadze Township after the Thermal Plant project had taken place. This was enough proof to the participants and the people of Cape Three points how disheartened it would be if that should happen to them too. They were of the view that, big trucks had already begun plying on their already deplorable roads since the area was cited for oil exploration. They opined that, the photographs presented were a wakeup call for them to demand whatever it is to make them feel better after the development has taken place in the area. Farm lands that were taken from the people of Aboadze have also been presented in Figure 3a and Figure 3b. Reclaimed farmlands and other personal land properties from the people of Aboadze that were under construction have also been presented in Figures 4a, 4b and 4c. Participants actually saw how their reclaimed lands would be put to use without getting any direct benefit. These were in vivid pictures for participants to see some of the construction sites that were earmarked and were under construction (see Figure 4c) for the building of the Thermal Plant at Aboadze. 


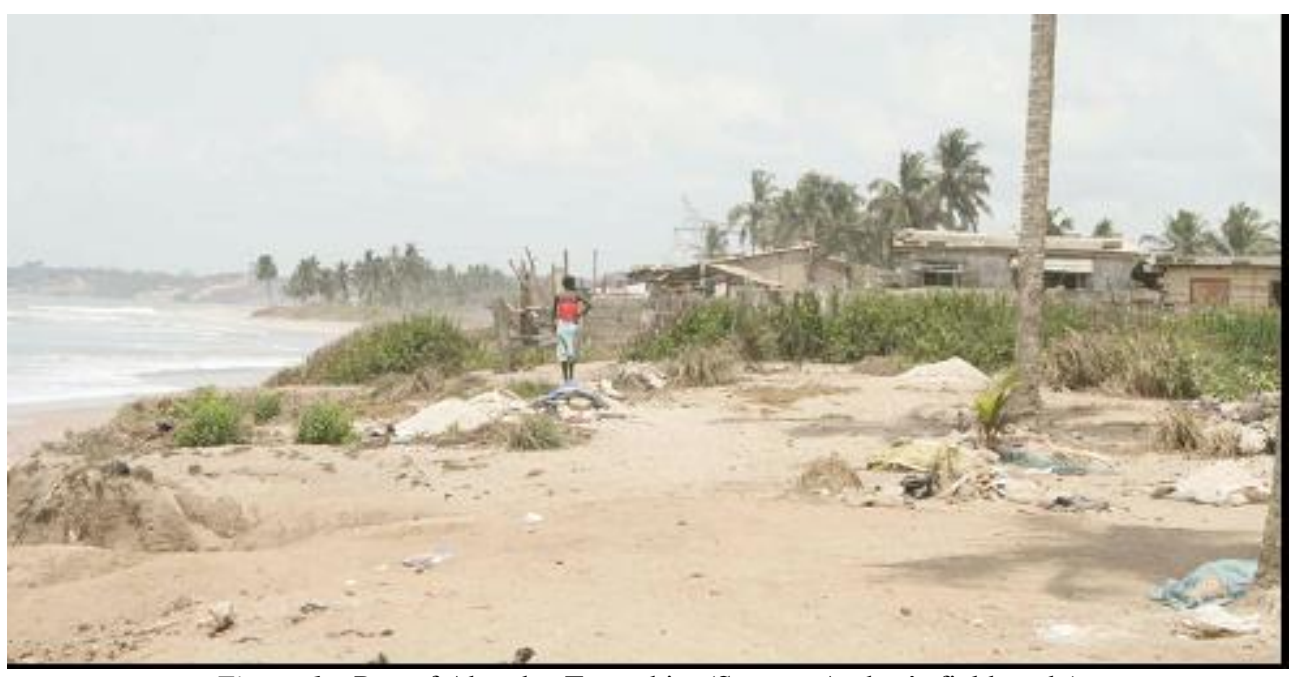

Figure 1a. Part of Aboadze Township. (Source: Author's field study)



Figure 1b. Part of Aboadze Township. (Source: Author’s field study)

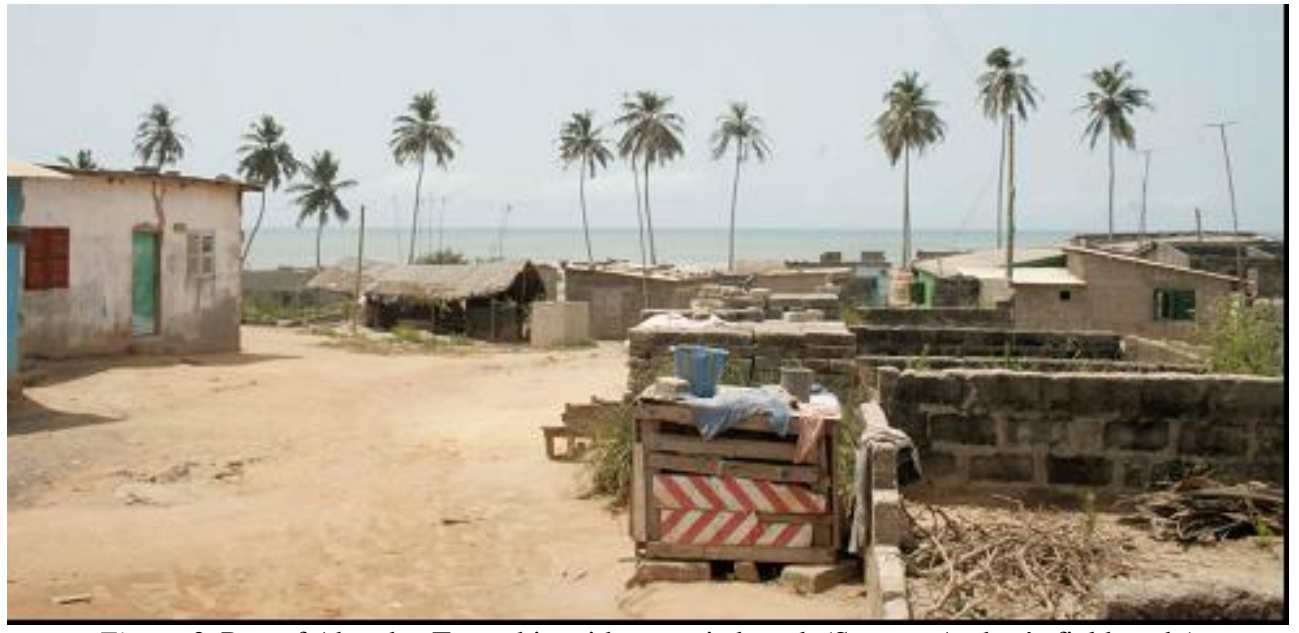

Figure 2. Part of Aboadze Township with an untied road. (Source: Author's field study) 


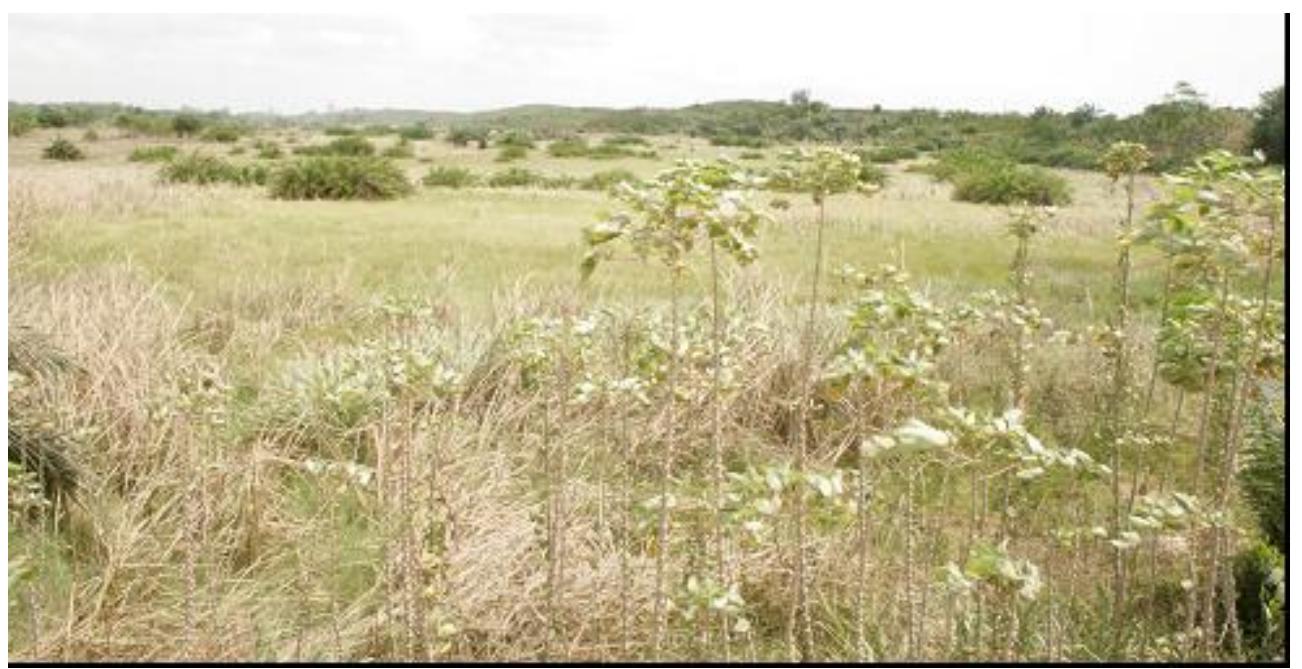

Figure 3a. Part of farm lands that were claimed from the people of Aboadze. (Source: Author’s field study)

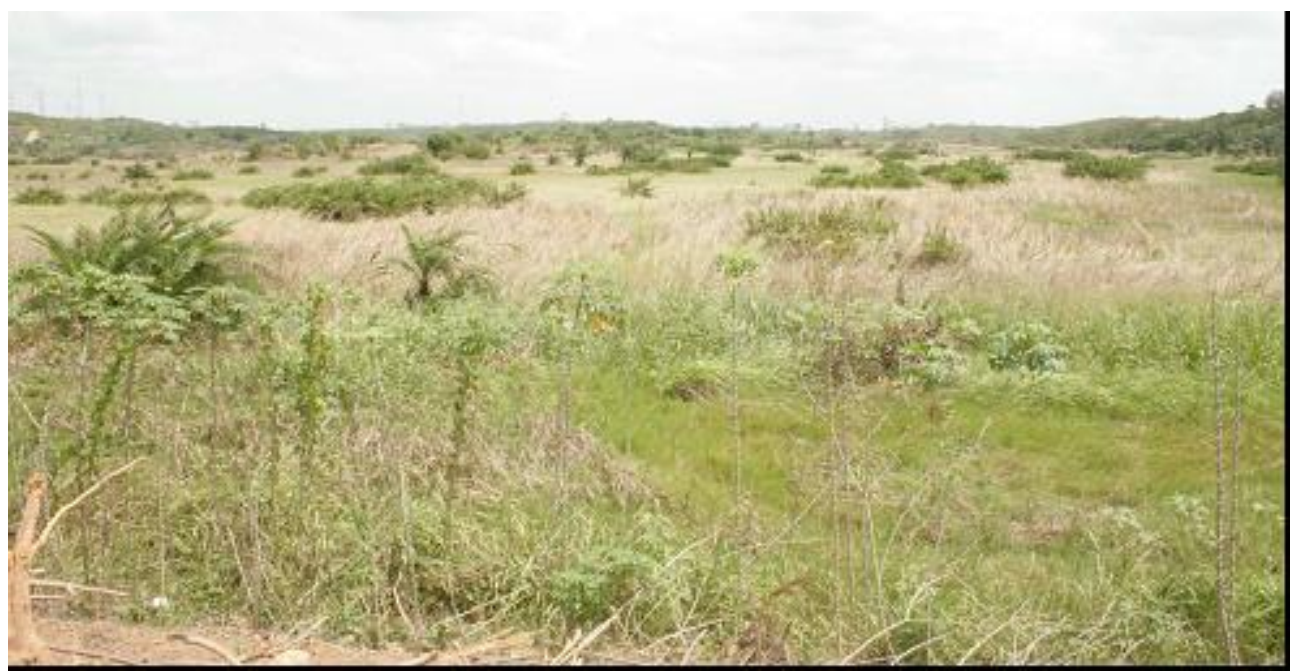

Figure $3 b$. Part of farm lands that were claimed from the people of Aboadze. (Source: Author's field study)

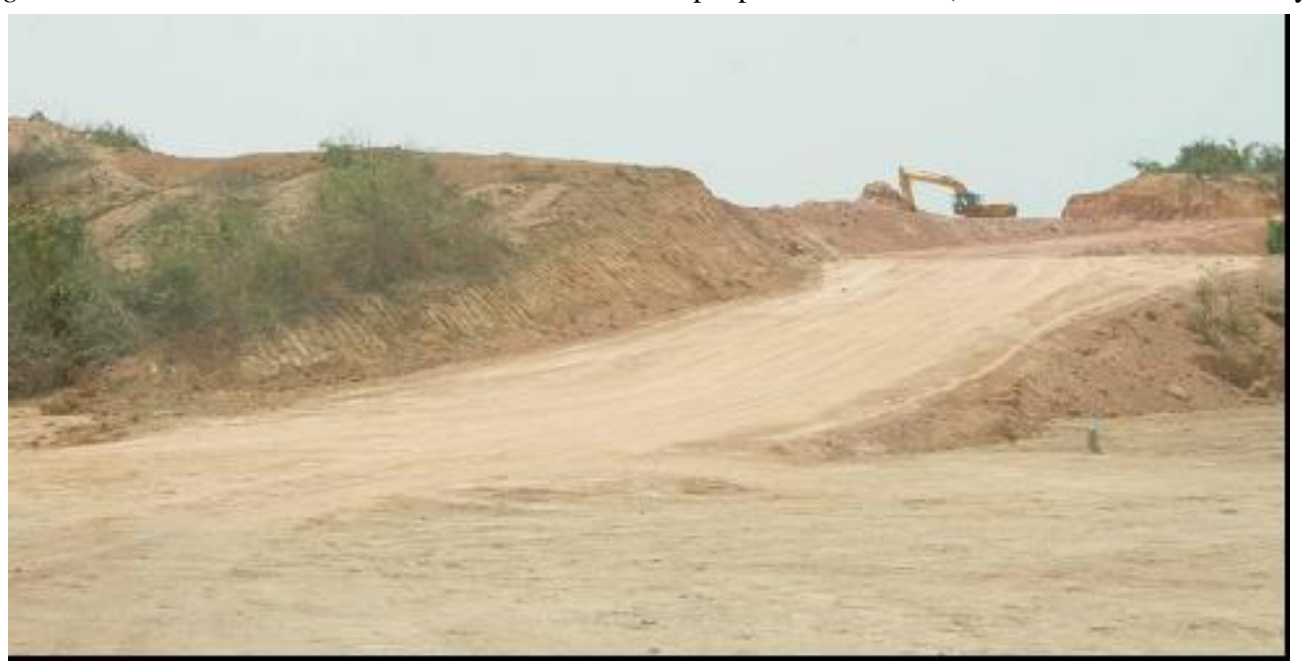

Figure 4a. Reclaimed farm land under construction. (Source: Author’s field study) 


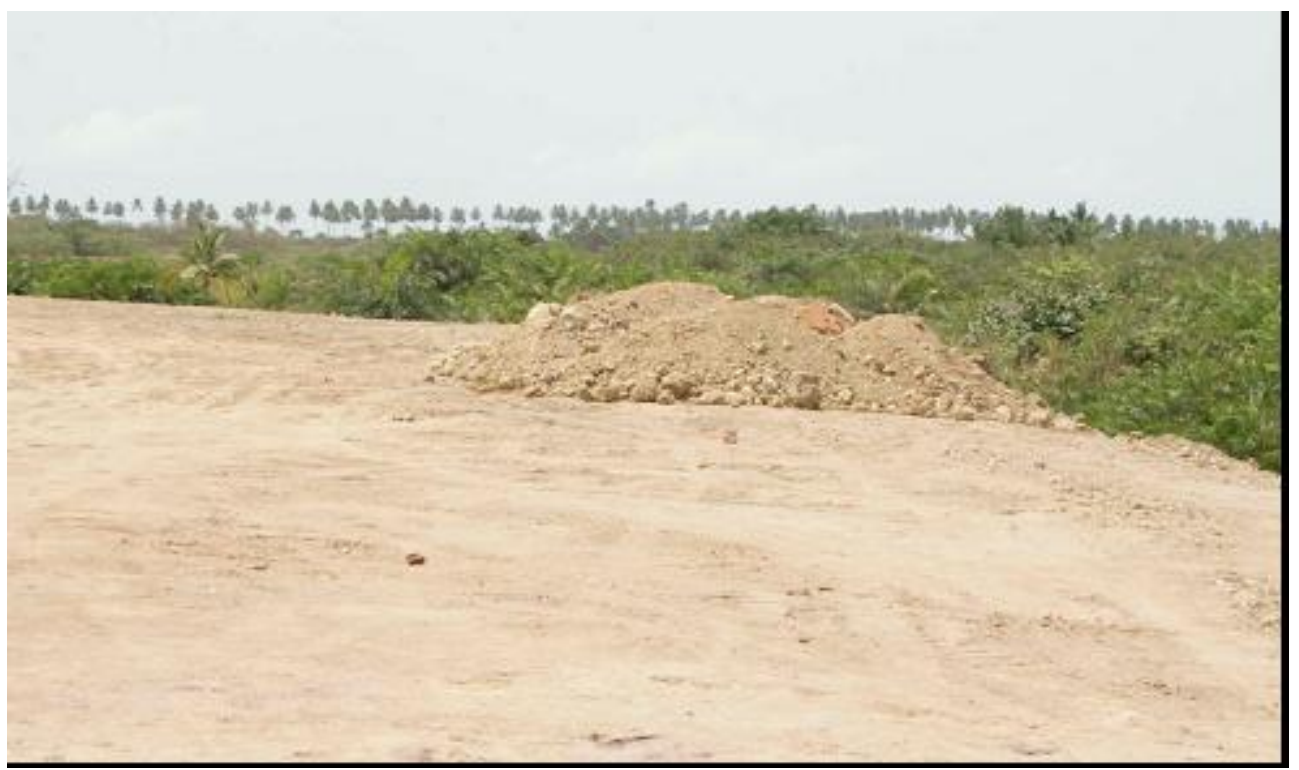

Figure 4b. Reclaimed farm land under construction. (Source: Author’s field study)

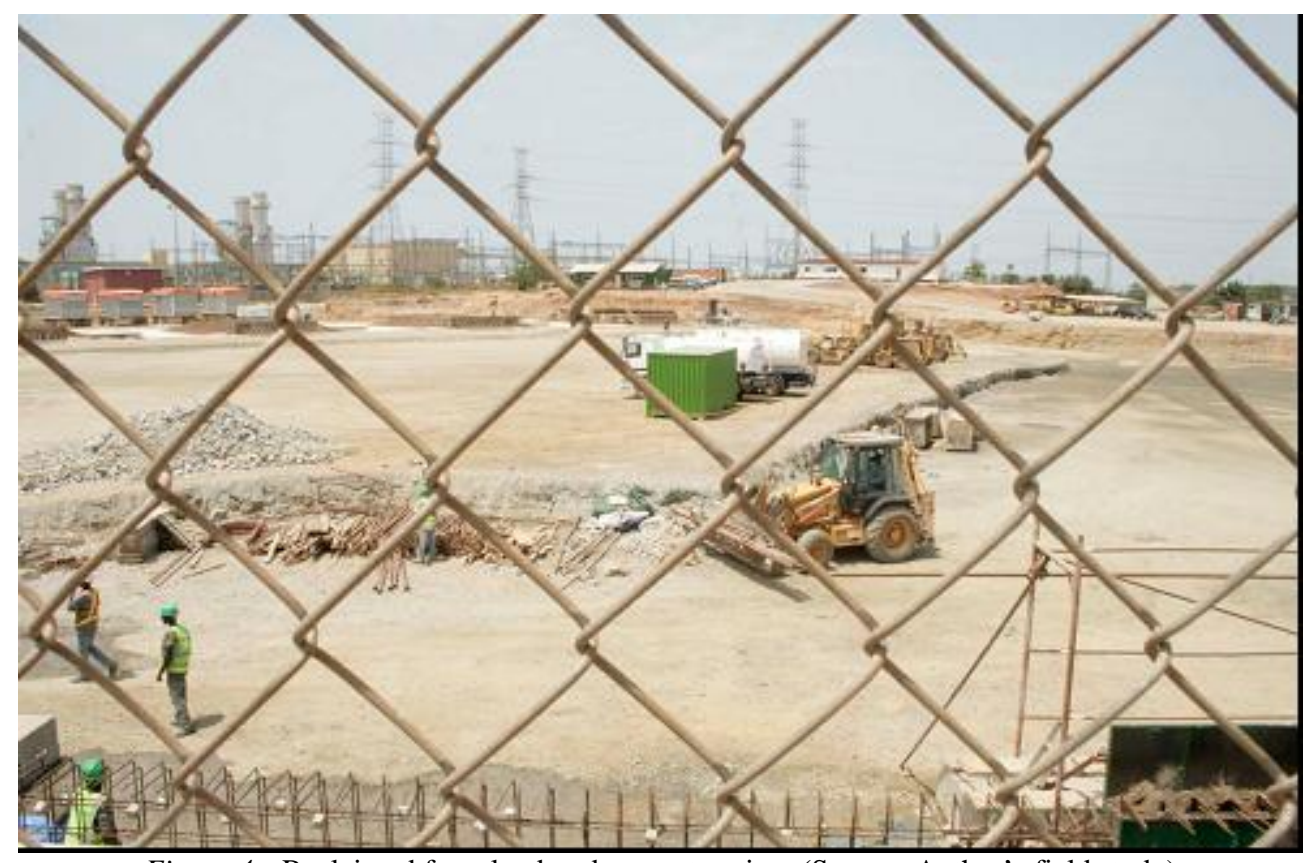

Figure 4c. Reclaimed farm land under construction. (Source: Author’s field study)

Participants were overwhelmed to see how the Volta River Authority worker's township has been built with asphalted road network, offices and a school facility (all presented in Figures 5, 6, 7, 8a and 8b) but could not find that in the Aboadze Township. They were so moved to see all these vivid pictures and how any such development could affect them in future if steps are not taken as it has happened to the people of Aboadze. 




Figure 5. Offices for the VRA workers under construction. (Source: Author's field study)

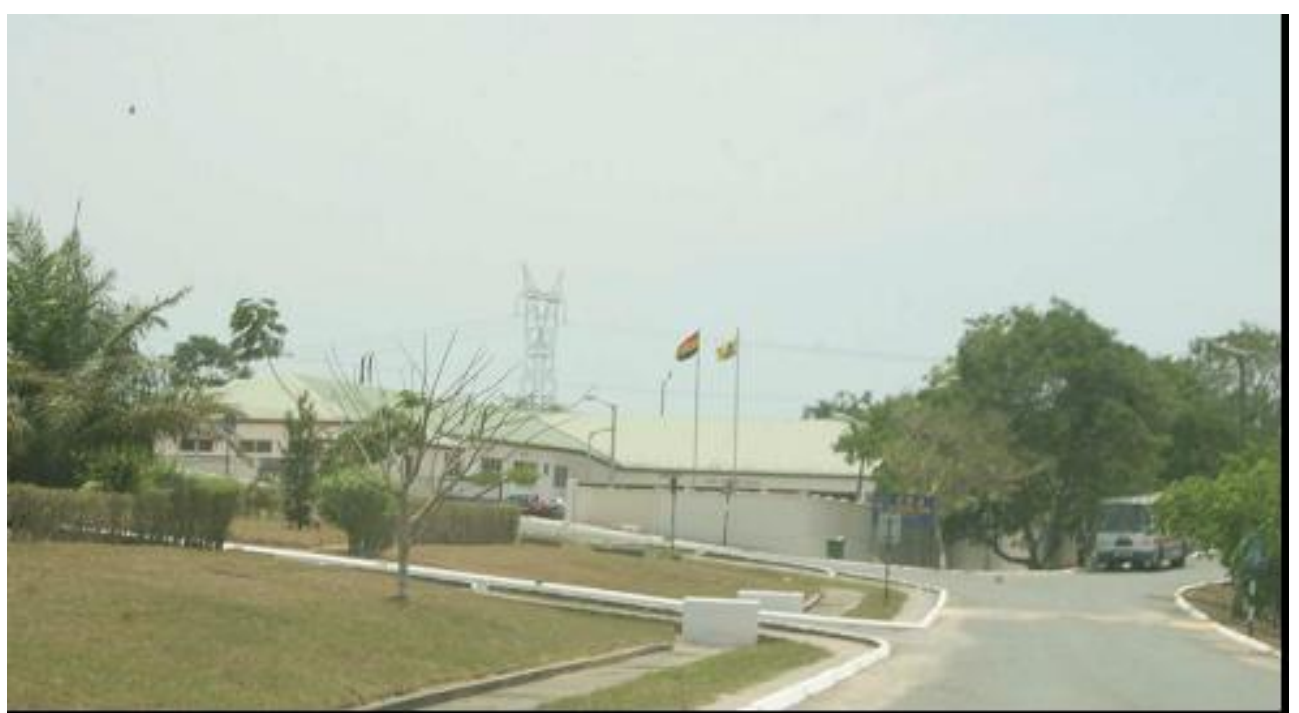

Figure 6. The VRA International School with beautiful road network. (Source: Author’s field study) 


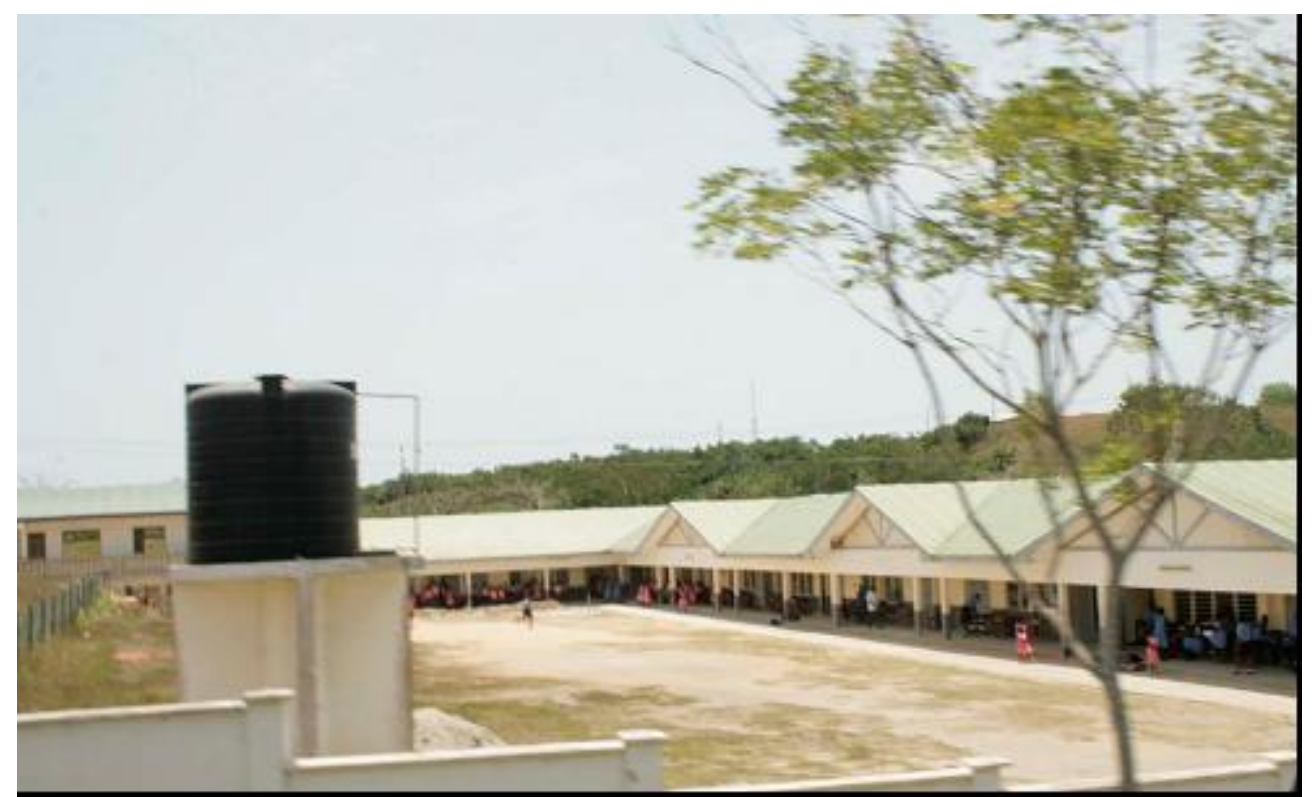

Figure 7. The VRA Internal School. (Source: Author’s field study)

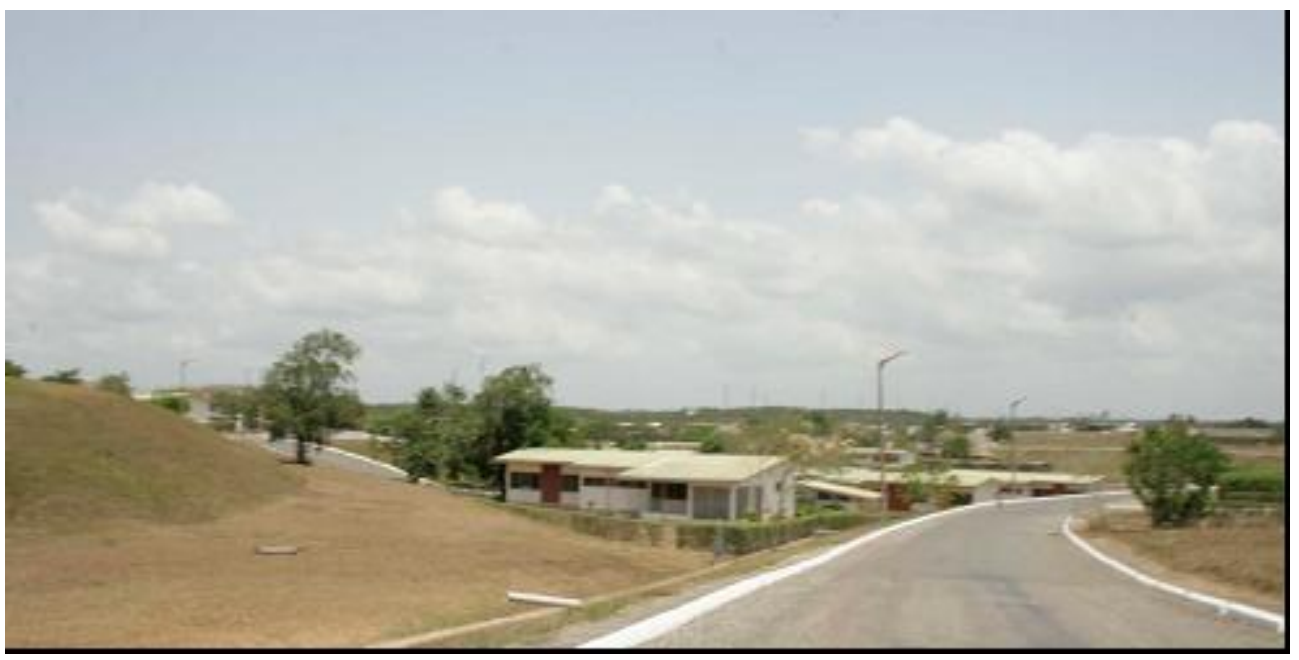

Figure 8. Landscape of the VRA Township. (Source: Author's field study)

Based on this experience, members of the group saw the effects and came to the realization that, because most properties such as houses, farmlands and other personal land properties are going to be destroyed and taken over by the government, due to the developmental projects, the government should first of all provide them with alternative resources to assist them as the developments go on. Secondly, some of the participants were particular about how to make ends meet if this should happen to them and suggested that, the fisher folks should also be given alternative territorial waters to operate because, Peprah (2011) states the fishermen in the communities have been cautioned not to fish in the areas where the oil has been cited. Participants realized that their livelihoods were at stake and needed to find ways to protect themselves against any eventuality. The workshop also gave some of the participant the insight to suggest that since their properties and places of work would be taken from them by the government, they should be provided with social amenities so that they do not suffer the way the people of Aboadze did during the building of the Thermal Plant as a point of reference. They also 
mentioned that social amenities like schools, portable water, hospitals and recreational centers be provided for the community.

Based on observations made by the participants from the illustrations on Aboadze community, the participants agreed that education for the youth is necessary to serve as an eye-opener to circumvent any unfortunate activities of the government if there should be any form of such developments.

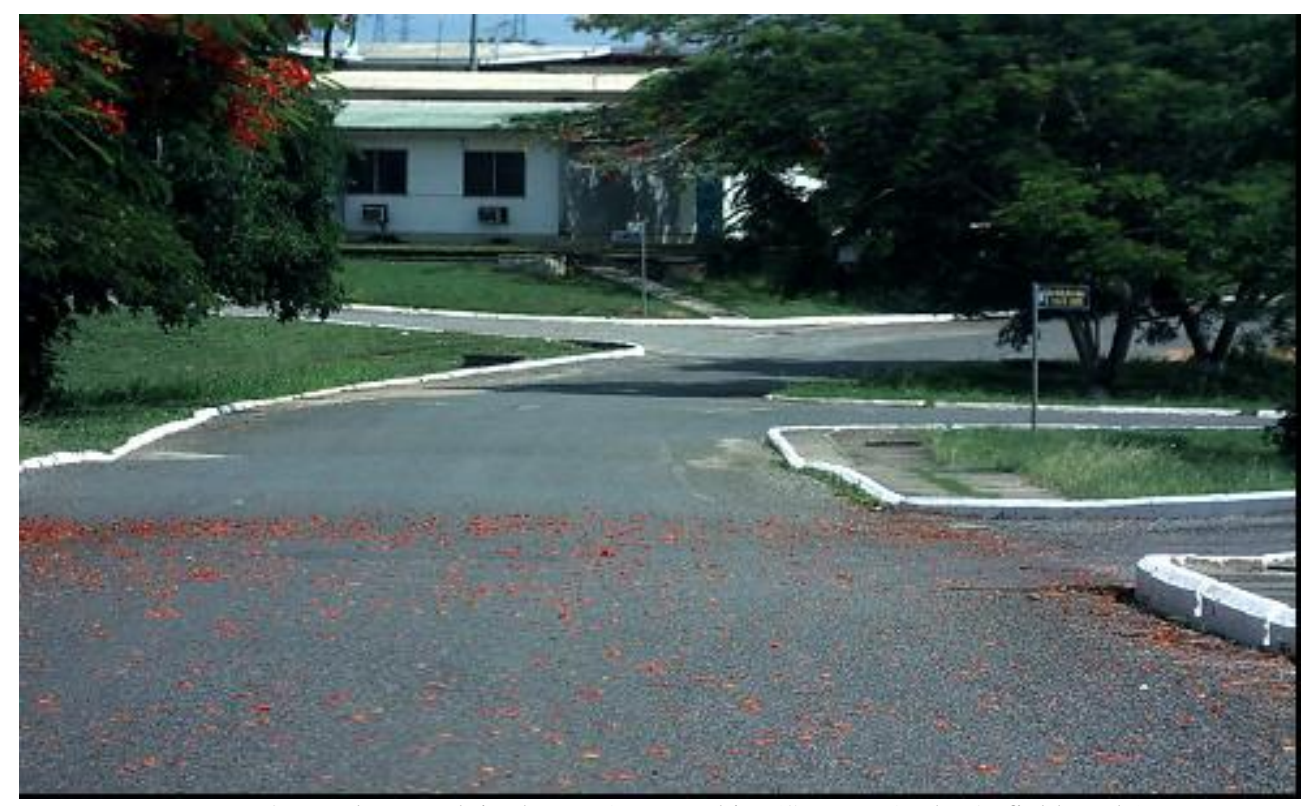

Figure 9. Road network in the VRA Township. (Source: Author’s field study)

It came to light that the rural folks could then realize the impact that development in the area could have on them. In view of this realization, members from the group became agitated and suggested means by which the government could also provide amenities and other incentives to better their lot.

It is apparent that many of our rural areas face significant challenges; some of our fishing, farming and forestry businesses still need to build their competitiveness. Generally, average income per head is lower in rural communities such as Aboadze and Cape Three Points. The skills base in rural communities in Ghana is narrower and the service sector is less developed. More so, teenage girls are not spared by the immigrant workers. These challenges as a matter of fact affect cultural practices and development of the people in such rural communities and the country as a whole.

\section{Conclusion}

It was evident during the workshop that if a pragmatic visual education is given to people within the CTP communities where rural developments are to take place, it would help them to know, understand and adjust to the socio-economic challenges that such developments may bring to the communities.

\section{Recommendations}

From the findings and conclusion of the study, it is recommended that:

1. There is the need for pictorial illustration to be used to educate the people of Cape three Points (CTP) rural communities. 
2. The government should provide fishermen, farmers and fish mongers in the CTP rural communities with alternate ventures that would adequately improve their lot.

3. The government should provide the communities with social amenities such as; provision of standard schools, scholarship schemes for brilliant children, standard health facility, good pipe-born water, well equipped recreational centres and the like.

4. The children in the rural CTP communities should be motivated to go to school since that would assist them to participate meaningfully in the developmental process in the communities and the country at large.

5. The youth, most especially young ladies in the CTP communities should be well educated to guard themselves against premarital sex by the immigrated workers.

\section{References}

Agriinfo.in. (2011). What is rural development. Retrieved 22/03/2011 from http://agriinfo.in/default.aspx?page=topic\&superid=7\&topicid=1443

Bracken, S. (2008). Defining rural community(ies): Future considerations for informal and nonformal adult education in rural communities. Retrieved 20/03/2014 from http://onlinelibrary.wiley.com/doi/10.1002/ace.288/epdf

Escobar, A. (1995). Encountering development: The making and unmaking of the third world. Princeton: Princeton Press.

Essuman, J. (2002). A manual on still photography for polytechnics in Ghana. Kumasi: KNUST Library.

Hall, S. (2014, March 28th). eHow Web site.com. Retrieved from http://www.ehow.com/about_5426494_define-socioeconomics.html\#ixzz2xG80tTKU

Hickey, S., \& Mohan, G. (2014, March 22nd). Relocating participation within a radical politics of development: Citizenship and critical modernism. Manchester: University of Manchester.

Levin Institute. (2014, March 22nd). Retrieved from http://www.globalization101.org/introduction-what-is-development-2/

Moon, B. K. (2014, April 2nd). Retrieved from http://www.un.org/millenniumgoals/bkgd.shtml

Moseley, M. J. (2003). Rural development: Principles and practice (1st ed.). London: Sage.

Nesterov, D. (2014, April 1st). Reasons why you need illustrations. Retrieved from http://www.w3illustration.com/custom-illustrations/news/reasons-why-you-need-illustrations/52

Ritchey, J. A. (2006). Negotiating change: Adult education and rural life in Pennsylvania. Pennsylvania Association for Adult Continuing Education. Journal of Lifelong Learning, 15, 1-16.

Schaefer, R. T., \& Lamm, R. P. (1995). Sociology (5th ed). USA: MacGraw-Hill Inc.

Spaulding, S. (2014, April 1st). Research on pictorial illustraton. Retrieved from Springer.onlinelibrary.wiley.com/doi/10.1111/j.1540-4781.1956.tb02145.x/full

Tella, R. D., MacCulloch, R. J., \& Oswald, A. J. (2001). Preferences over inflation and unemployment: Evidence from surveys of happiness. Retrieved from http://www.jstor.org/stable/2677914?seq=2\#page_scan_tab_contents

The Business Dictionary. (2014, March 22nd). Retrieved from http://www.businessdictionary.com/definition/development.html us.wow.com. (2014, March 24th). Retrieved from http://us.wow.com/wiki/Rural_development?s_chn=9\&s_pt=aolsem\&v_t=aolsem Williams, T. (2014). What are socioeconomic issues? Retrieved 28/03/2014 from

http://www.ehow.com/info_8045579_socioeconomic-issues.html

www.buzzle.com. (2011, October 13). Retrieved from http://www.buzzle.com/articles.cultures.\%20html 